\title{
Histórias de vida sobre o fenômeno depressivo
}

\author{
Life stories on depressive phenomenon
}

Modesto Leite Rolim Neto', Alberto Olavo Advincula Reis', Carlos Augusto Carvalho Vasconcelos², Nádia Nara Rolim Lima ${ }^{3}$, Jesus de Souza Cartaxo ${ }^{4}$, Marina Lucena de Aguiar Ferreira ${ }^{5}$, Jesualdo Alves Duarte Júnior ${ }^{5}$

\section{Resumo}

Objetivo: Avaliar a importância do processo narrativo na descrição dos significados envolvidos no fenômeno depressivo. Métodos: A população pesquisada compreendeu 324 pacientes, que procuraram os serviços clínicos e psicológicos no Posto de Saúde Auta Alves Ferreira, na cidade de Aparecida e no Hospital Municipal de Santa Cruz, localizados no interior da Paraíba, tendo como motivo da consulta sofrimento e/ou dor psíquica. Desses, foi composta uma amostra de 159 pacientes, incluindo adolescentes e adultos, de ambos os sexos. Para coleta de dados, utilizou-se a entrevista narrativa. A análise das entrevistas seguiu o procedimento delineado por Schutz. Resultados: As narrativas proporcionam a oportunidade ímpar de rever conceitos, discutir histórias de vida e ouvir posicionamentos no (re)contar episódios relativos à depressão. Conclusão: As narrativas constituem-se em fator determinante no considerar, por meio da palavra, os conflitos inerentes à tentativa de uma escuta comprometida à vivência da depressão.

Palavras-chave: depressão; narração; dor; estresse psicológico.

\begin{abstract}
Objectives: To evaluate the importance of a descriptive narrative process of the meanings involved in a depressive phenomenon. Methods: The research population consisted of 324 patients, who attended the Posto de Saúde Auta Alves Ferreira, in the city of Aparecida and Hospital Municipal de Santa Cruz, located in the central area of the Paraiba State, for clinical and psychological health care. The main reason for consultation was suffering and/or psychological pain. A sample of 159 patients was taken, including male and female adolescents and adults. Data were collected through a narrative interview. Shutz' procedure was used for information analysis. Results: The obtained data offered the opportunity to review concepts, to discuss life history, and to listen to narrative positioning episodes of manifested depression. Conclusion: The narratives were considered to be a determinant factor to consider inherent conflicts of a compromised listening to the depression living.
\end{abstract}

Keywords: depression; narration; pain; stress, psychological.

Recebido em: 13/06/2011

Revisado em: 28/08/2011

Aprovado em: 15/09/2011

\footnotetext{
Trabalho realizado na Faculdade de Medicina do Cariri, Universidade Federal do Ceará (UFC) - Juazeiro do Norte (CE), Brasil.

Faculdade de Saúde Pública da Universidade de São Paulo (USP) - São Paulo (SP), Brasil.

2 Departamento de Neuropsiquiatria e Ciências do Comportamento da Universidade Federal de Pernambuco (UFPE) - Recife (PE), Brasil.

${ }^{3}$ Secretaria de Políticas Públicas para Mulheres - Cajazeiras (PB), Brasil.

${ }^{4}$ Hospital Regional de Cajazeiras - Cajazeiras (PB), Brasil.

5 Faculdade de Medicina do Cariri, Universidade Federal do Ceará (UFC) - Juazeiro do Norte (CE), Brasil.

Endereço para correspondência: Modesto Leite Rolim Neto - Avenida Tenente Raimundo Rocha, SN - Cidade Universitária - CEP: $63048-060$ -

Juazeiro do Norte (CE),Brasil-E-mail: modestorolim@yahoo.com.br.

Fonte de financiamento: M.L.A.F. recebeu bolsa PIBIC/CNPq/UFC e J.A.D.J. recebeu bolsa PIBIC/FUNCAP/UFC.

Conflito de interesse: nada a declarar.
} 


\section{Introdução}

Na perspectiva de compreender os deslindes inerentes ao fenômeno depressivo, houve acesso a um sem-número de hipóteses, teses, disposições textuais e empíricas que possibilitam analisá-lo sob diversas óticas ${ }^{1,2}$. Assim, para melhor delinear essa compreensão, necessário se faz adotar critérios definidos de avaliação e experimentação, com o escopo de tentar delimitar seu caráter peculiar de imprevisibilidade.

Nessa medida, o critério, ou perfil, mais adequado para viabilizar o entendimento lógico da depressão faz-se pela análise da narrativa do paciente, que constitui atualmente tendência metodológica inovadora e humanizada na forma de compreender, estudar e formular pretensões acerca das reorganizações efetuadas a partir de histórias que são contadas em face de sua patologia.

Com a vivência da doença, as pessoas passam a ter outra história para contar. Essas histórias não são separadas do processo de viver, mas são convergentes à maneira de ver o mundo e de viver nele, passando a integrar-se ao mesmo. Elas relatam várias situações vividas que, no seu conjunto, têm um sentido maior, o que as transforma em histórias acessíveis aos outros ${ }^{3}$.

Daí considerar-se, sob o olhar da depressão, que a análise do processo narrativo nas manifestações do fenômeno depressivo, por intermédio de parâmetros estabelecidos e fixados pelo portador da doença, por meio dos significados, busca relacionar o presente com o passado e refletir o presente face seu suposto e desejado 'presente'. Assim sendo, existe tão somente uma perspectiva tímida de futuro, negativada pela insatisfação e, sobretudo, revolta com o status depressivo. Nessa perspectiva, as apreensões que constituem as narrativas dos sujeitos compõem a sua representação da realidade e, como tais, estão prenhes de significados e reinterpretações ${ }^{4}$, delineadas pela sua matriz de sentido.

Portanto, a compreensão sobre a narrativa da depressão proporciona interpretação dos jogos da verdade nos espaços da linguagem, historicizando-as no que comporia uma condição de existência da doença, por meio de perspectiva, eminentemente, valorativa dos conceitos preestabelecidos, os quais se modificam e ganham nova entoação perante o caráter enunciativo da doença 5 .

A prática discursiva é um conjunto de regras anônimas, históricas, sempre determinadas no tempo e no espaço, que definiriam, numa dada época e para uma determinada área social, econômica, geográfica ou linguística, as condições de exercício da função enunciativa ${ }^{6}$.

Esse ponto de partida remete à reflexividade sobre os interlocutores que permeiam a narrativa sobre a realidade da doença, quanto à produção da história pertencente a essa realidade. A narrativa, como meio de buscar a verdade, encontra em seus itinerários palavras, ações, coisas, olhares e saberes que advêm do seu elemento de conflito. Destaca-se que o conflito cria uma tensão que organiza os fatos da história ${ }^{7}$. Percebe-se, ainda, que o conflito determina uma (re)invenção do fato, favorecendo uma interpretação ou leitura dos tempos e lugares caracterizados pelo que está à disposição para ser polido, decifrado, aquilo que é enunciado pelo discurso.
Essa compreensão, provavelmente, é que tem subsidiado o pensar sobre as vozes sem nome, anônimas, precedidas desde há algum tempo nos seus interstícios, ao se manterem um instante em suspenso ${ }^{8}$. Julga-se necessário resgatar esse instante pela perspectiva da narrativa, intercruzando uma reflexão sobre as histórias que são contadas no encontro das palavras, uma possibilidade de aceno ao que é singular, temível, depressivo, suspenso naquilo em que o real constitui numa enunciação. Desse modo, as pessoas, ao narrarem suas vivências, abrem seus discursos de modo a permitirem a apreensão de sua significação por outras pessoas ${ }^{3}$.

Devo dizer palavras enquanto as houver. Devo dizê-las até que elas me encontrem. Até elas me dizer - estranha dor e faltaª. Esse desejo de encontrar o tempo e o espaço naquilo que se vive, sobrepõe-se ao limiar das histórias vividas em torno da doença. Eis uma das razões de entendê-las como prática social, embrenhada de velhas e novas palavras. Assim, a depressão encontra na palavra uma prática discursiva, enquanto condição de resposta a uma história de dor e/ou sofrimento psíquico, por meio de uma enunciação, expressada no dizer.

Nesse exercício, a palavra dita e interdita arrisca a percorrer o caminho que abre as histórias no movimento dos fatos, dos personagens, nas lacunas que as palavras deixam na dimensão do relato que ousa dizer seus nomes, seja nas inquietações, seja na dor de $\operatorname{ser}^{10}$, sobretudo naquilo que o tempo e o espaço territorizam como verdade sobre o incômodo que desarma o discurso, mas que, segundo seu trajeto, atravessam as palavras nas reconstituições dos acontecimentos. As histórias contadas libertam-se de seu ambiente original discursivo ou representativo, passando a serem entextualizadas ${ }^{11}$.

Ninguém diz nada sem ter ouvido dizer - e sem estar neste ou naquele lugar, sem ser ele próprio qualquer coisa diferente dele próprio ${ }^{12}$. Apesar de achar que isso ocorra, far-se-ia um acréscimo, na (re) constituição desse exercício, por meio de um elemento discursivo, simultaneamente veiculado, oralizado, que provoque uma materialidade a fim de compreender a posição desse discurso face ao percurso da verdade sobre a doença e ser/estar doente.

Acredita-se que, ao se interrogar sobre as coisas ditas e interditas, o depressivo encontra a medida do entrelaçamento entre o que é dito e escutado e o que é lido sobre a história narrada. De uma maneira ou de outra, as coisas ditas mostram muito mais do que elas próprias ${ }^{13}$. De certa forma, o dizer pressupõe uma construção possível àquilo que se quer traduzir e para o qual se busca uma resposta, por meio das aproximações com a palavra, permitindo, na coisa dita, um desejo de partilha no interior da história, no (re)encontro com um saber, o qual possa contribuir para a enunciação de acontecimentos e contingências, perante o que se anuncia como possibilidade de discurso. As coisas interditas, por seu turno, postam-se entre o dizer e o discurso para possibilitar o enfrentamento de ideias e ideais em persecução.

Assim, as palavras ditas pelo depressivo trazem mais enunciados do que tentam transparecer, como também carregam, em seu trajeto, uma infinidade de expectativas interditas, enrustidas no discurso, à medida que esse irrompe conforme uma série de reflexões e especificidades no reco- 
nhecimento da própria verdade, buscada por meio da tradução de sua narrativa. A doença, portanto, está alicerçada na historicidade humana e em sua temporalidade, sendo constituída por uma rede de perspectivas ${ }^{14}$.

\section{Métodos}

Buscou-se compreender as narrativas com fins de pesquisa social, reconstruindo-se os acontecimentos a partir da perspectiva do informante, tão diretamente quanto possível ${ }^{15}$. Numa busca do quê, de como os envolvidos na recontextualização daquilo que provoca, ao falar, uma maneira própria de traduzir a situação narrada ${ }^{16}$. Fundamental, nesse processo, é não perder de vista o modo como os sujeitos falam sobre suas vidas, a linguagem usada e as conexões realizadas ${ }^{17}$. Abordar as narrativas, como método de investigação, pressupõe entendê-las não apenas como uma listagem de acontecimentos, mas uma tentativa de ligá-los, tanto no tempo, como no sentido ${ }^{15}$.

A população pesquisada compreendeu 324 pessoas, na faixa etária de 10 anos ou mais, as quais procuraram os serviços clínicos e psicológicos no Posto de Saúde Auta Alves Ferreira, na cidade de Aparecida, e no Hospital Municipal da cidade de Santa Cruz, localizados no interior da Paraíba, tendo como motivo da consulta circunstâncias que envolviam sofrimento ou dor psíquica. Num primeiro momento, efetuou-se, por meio dos prontuários, um levantamento dos sujeitos, a partir das notificações de casos. De posse dessas informações, começou-se a mapear a amostra, considerando-se: o número de visitações aos referidos campos de investigação; o tratamento farmacológico prolongado para depressão e/ou doença dos nervos; o histórico de uma ou mais recorrência no mesmo ano; o histórico com indicadores de ideação suicida; e o histórico com tentativas de suicídio.

Constituíram-se, a partir desse mapeamento, três critérios de inclusão da amostra, baseados em diagnósticos do CID-10, levando em consideração: ser portador de depressão; ser portador de ideação suicida; e ser portador de histórico de tentativa de suicídio.

A amostra foi composta por 150 sujeitos, incluindo adolescentes e adultos de ambos os sexos, por aproximação aos critérios de inclusão. Tratou-se, neste caso, de amostra proposital (purposeful sampling), enquanto seleção de casos ricos em informação para um estudo em profundidade, modalidade padrão $0^{18}$.

\section{Instrumento}

Foi utilizada como instrumento de coleta de dados a entrevista narrativa (gravada na íntegra), tendo em vista situações que encorajassem e estimulassem o informante a contar sua história, mediante um acontecimento importante de sua vida e do contexto social. É considerada uma forma de entrevista não-estruturada, de profundidade, com características específicas ${ }^{15}$, contrastando diferentes perspectivas e levando a sério a ideia de que a linguagem, assim como o meio de troca, não é neutra, mas constitui uma cosmovisão particular ${ }^{19}$.

\section{Análise de dados}

Procurou-se analisar as entrevistas por meio de seis $\operatorname{passos}^{15}$ : transcrição detalhada das expressões verbais dos sujeitos da pesquisa; divisão do texto em material indexado e não-indexado, as proposições indexadas tinham como referência concreta quem fez o quê, quando, onde e por quê, enquanto que as não-indexadas consideravam os acontecimentos, valores, juízos e toda a forma de uma generalizada "sabedoria de vida"; uso de conteúdos indexados, para analisar o ordenamento dos acontecimentos de cada pessoa; investigação das dimensões não-indexadas; compreensão do agrupamento e comparação entre as trajetórias individuais; comparação de casos e trajetórias individuais, dentro do contexto, e estabelecimento de semelhanças.

Para a construção do perfil cartográfico das narrativas orais, utilizou-se a estratégia de triangulação de pesquisadores ${ }^{18}$. Três pesquisadores leram as entrevistas, provocando o processo de reflexividade, e posterior decodificação dos referenciais que subsidiaram as narrativas, destacando pontos relevantes para o mapeamento dos dados. Vale ressaltar que as medidas, no que concerne à ética em pesquisa com seres humanos, foram efetuadas.

\section{Resultados e Discussão}

Para o depressivo, na relação com o outro, o meio de extravasar a manifestação da doença em si é o dizer, contar e (re) contar, que são postos em suspenso por fatores temporais na tradução de sua própria história. O profissional, em geral, simplesmente avalia os sintomas pela verdade clínica e margeia a narrativa do paciente, que, via de regra, possibilitar-lhe-á conhecer, com riqueza de detalhes, a forma como a depressão se lhe apresenta. Aquilo que efetivamente é dito não provém de um tesouro infinito de significações, mas de condições e possibilidades específicas ${ }^{12}$.

Necessariamente, o discurso do depressivo é composto por enunciações pautadas na busca incessante de uma resposta, uma verdade capaz de explicar e elucidar questionamentos estereotipados no mundo que o envolve, em uma relação espaço-temporal. Essa visão revela a possibilidade de ouvir o dito pelo depressivo e, então, perceber como se apresenta a patologia perante suas expectativas pessoais e interpessoais. Veja-se o que ensina, acerca da depressão, uma paciente escutada, aos 57 anos de idade: "É angústia, é frio, [...] é peleja o ano inteiro, uma coisa ruim que vai matando a gente. Começa devagar, depois vai aumentando, tirando a vida. É coisa esquisita, não tem hora para chegar. Parece fogo em tempo de broca".

Escutar o dito é bem mais viável, porque dispõe de consistência material, mas compreendê-lo implica margear a exigência de um discurso ordenado e sentir, axiologicamente, o desejo e as perspectivas que a depressão emprega na sua vítima, ou seja, as coisas interditas pelo discurso. 
O novo não está naquilo que é dito, mas no acontecimento do seu retorno?. Por isso, a narrativa, em sua representação da realidade vivi$\mathrm{da}$, ressalta o contar histórias, liberadas com a força que o paciente lhe atribui, como forma de montar um diálogo, cujo retorno depende de mútuas regras de captação da palavra. Como se vê a possibilidade de se contemplar o interdito proporciona a compreensão de que, mesmo em condições normais, o ser humano traz na sua palavra, polida pelo regramento social, a ideia implícita em seu desejo real e subjetivo. O depressivo, adstrito aos conflitos internos e externos da doença, emite, em sua palavra, o interdito, do modo mais fluente e perceptível, capaz de determinar os pontos nevrálgicos e circunstanciais do fenômeno. Não sendo ele escutado ou sendo retido na relação com o outro, a palavra fica mascarada e aprisionada na tempestade interna que se forma no interior do indivíduo. Na verdade, a listagem de sintomas é o que prevalece; a singularidade do sujeito e sua história de vida ficam relegadas ${ }^{10}$.

Um paciente de 38 anos, amparado pela previdência por auxíliodoença, com histórico de suicídio, desabafa: “A depressão é como um maracujá, tudo envelhece, criando rugas no coração e na emoção. O que salva é a fé, mais aí vem à confusão, a agitação, a ansiedade, as frustrações [...] sou um baú velho cheio de recordações".

$\mathrm{Na}$ órbita da patologia, a reflexividade sobre a narrativa proporciona ao depressivo a oportunidade ímpar de rever seus conceitos, discutir sua história de vida e ouvir um posicionamento racional, ao (re) contar episódios reunidos. Em toda a sociedade, a produção do discurso é simultaneamente controlada, selecionada, organizada e redistribuída por certo número de procedimentos, que tem por papel exorcizar-lhe os poderes e os perigos, refrearem-lhe o acontecimento aleatório e disfarçar a sua pesada temível materialidade ${ }^{8}$.

Nesse sentido, as narrativas não são meras descrições da realidade, são especialmente produtoras de conhecimentos que, ao mesmo tempo em que se fazem veículos, constroem os condutores ${ }^{4}$. Observou-se que a oralidade não significa somente o início do discurso, mas o veículo utilizado pelos pacientes para mediar as sensações ou o fim da exposição dessas sensações.

Um outro paciente, com 42 anos, que trabalha como ferreiro, revela que: “A depressão é como soda cáustica, corrói tudo por dentro. É tremura no corpo, as pernas ficam um mulambo. Tudo dói, tudo lateja, é suor frio". O discurso é um canal para divulgação daquilo que se perfaz por intermédio da tradução de uma vontade de verdade sobre as experiências vividas e compartilhadas em meio à dor e ao sofrimento psíquico.

Só aparece, portanto, aos olhos uma verdade insidiosamente universal. Ignora-se, em contrapartida, a vontade de verdade como prodigiosa maquinaria destinada a excluir todos aqueles que, na história, procuraram contornar essa vontade de verdade e recolocá-la em questão contra a verdade?

Assim, a ordem do discurso, analisada com acuidade pelas narrativas, faz perceber que ela é capaz de modificar a forma como as pessoas compreendem a si própria e aos outros. É um verdadeiro entrelaçamento entre o dizer e o relacionar pensamentos, sempre em um movimento que envolve ação, reflexão e reação. Nesse mesmo diapasão, é fácil e igualmente complexo perceber que a narrativa compreende uma conjuntura de significados e interpretações da patologia psíquica, vivida pelo paciente, que se reflete na sua estrutura clínica e no seu convívio social e familiar. Observe como uma jovem, de 23 anos, traduz essa postura: "A depressão é como uma flor que murchou, nem sequer vingou, é só ramo seco pedindo água. O silêncio é nosso maior intérprete”. Ocorre, contudo, uma sensível modificação no significante e no significado das coisas lidas pelo depressivo, leitura essa em sentido lato. Todo conhecimento é autobiográfico ${ }^{20,21}$, porque emana da percepção subjetiva dos elementos objetivos.

O fenômeno depressivo, sob a ótica da narrativa, faz determinar que a palavra dita e interdita constituía-se em um fator determinante para viabilizar a complexidade de estabilização da doença, especificamente quando o intérprete oferece sua 'escuta' ao depressivo, na tentativa de ouvir o dito e perceber o embutido na sua palavra de massacre, sofrimento e dor. O interdito, assim, é o período de transição entre o dito e o que se está por dizer, devendo ser considerado como fonte basilar dos mecanismos a serem utilizados na pretensa possibilidade de 'cura' do doente.

O posicionamento do depressivo ocorre por meio do incessante desejo de libertação de um aprisionamento psíquico que o incomoda, que o faz refletir para sofrer, em uma relação constante e interdependente entre tempo - passado/passado, passado/presente, presente/presente e ausência de futuro. Esse intenso exercício de reflexividade no sentir a dor de ser do depressivo caracteriza o momento crucial da doença.

Nesse momento, a escuta é a sua válvula de escape, a oportunidade de contar sua história de vida para desabafar seus anseios e proporcionar, ao intérprete, que enxergue os meios de estagnação da patologia. Acredita-se que a dor precisa ser transformada, mas não esquecida; contrariada e obliterada ${ }^{22}$.

A palavra dita e interdita, no entanto, é o meio capaz de viabilizar a transformação da dor de ser do depressivo, bem como o combustível para alimentar a contrariedade dos males por ela causados. Alerte-se que o grau de complexidade da depressão encampa no território da estabilização da doença, visto que o tratamento não depende somente dos meios e objetivos empregados pela evidência. Não obstante sua relevância nesse processo, o controle da depressão está, intimamente, relacionado ao animus do paciente, que, comprometido com a dor de ser, tem que ser libertado de si mesmo para dominar a doença. Daí a relevância da narrativa para provocar a compreensão da vivência de dor e/ou sofrimento psíquico, acarretados pela depressão, por meio da escuta comprometida como subsídio para o diagnóstico.

A ordem da depressão é veiculada entre o dizer, assim como pelo interdizer, mas é refletida a partir de um dado enunciado no expor a vontade própria de tradução às necessidades do que é vivido, como real ao tempo da doença e do doente.

Destarte, a 'escuta' entra em cena como elemento facilitador e indispensável ao depressivo e ao seu tratamento porque, a partir dela, 
será disponibilizada, em palavras, o que efetivamente incomoda o doente. Os sintomas da doença refletem-se na sua psiquê e, notadamente, possibilitará ao intérprete a oportunidade de soltar as amarras do doente para, enfim, libertá-lo do mais grave sintoma da depressão: a dor de ser/estar depressivo. Essa dor deve ser escutada porque é dita, descrita, articulada, ansiosamente, pelo depressivo com bastante propriedade e, sobretudo, pelo desejo de 'cura'23.

De modo mais aprofundado, a narrativa revela tendência inerente aos pacientes no buscar, incessantemente, um começo, possuir um guia para o seu discurso, de modo a depositar as informações ditas e interditas para traduzir seus anseios. Portanto, o medo de não ter a escuta à sua disposição transforma o depressivo em seu próprio carrasco, trazendo sentimentos de "morte", a tradução de sua dor e/ou sofrimento psíquico. Neste, a história de vida é fragmentada em nome da vontade do saber clínico.
Mas o que há assim de tão perigoso pelo fato de as pessoas falarem, qual o perigo dos discursos se multiplicarem indefinidamente? Onde é que está o perigo?8 ${ }^{8}$. No contexto da depressão, a dor de $\operatorname{ser}^{10}$ reflete-se no tempo da doença e do doente, aproximando-os dos fatores envolvidos aos saberes inscritos à patologia, que influencia na ruptura da estrutura discursiva.

Codinominando-se como doente dos nervos, os pacientes narram o que é deveras relevante ao saber popular no processo de releitura e/ou reconstrução do seu cotidiano de dor e sofrimento psíquico. A história é um discurso de bases narrativas ${ }^{22}$, pois se fundamenta no enredo que é traçado e até determinado pelo historiador. Nesse sentido, dizer/escutar formam um binômio indissociável para a compreensão dos saberes clínicos e populares, principalmente no resgatar o dizer do paciente acerca da doença, e o escutar do intérprete, ouvindo o interdito entrelaçado às suas palavras.

\section{Referências}

1. Almeida Filho N, Mari JJ, Coutinho E. Estudo Multicêntrico de morbidade psiquiátrica em áreas urbanas brasileiras. Rev ABP-APAL. 1992;14:93-104.

2. Weissman MM, Bland RC, Canino GJ. Cross-national epidemiology of major disorders. 3 ed. (DSM-III). Washington DC: American Psychiatric Press; 1996.

3. Silva DGV, Mercedes T. Narrativas como técnica de pesquisa em enfermagem. Rev Latino-am Enferm. 2002;10(3):423-32.

4. Cunha MI. Conta-me agora: as narrativas como alternativas pedagógicas na pesquisa e no ensino. Rev Fac Educ. 1997;23(1-2).

5. Rabelo MC. A construção narrativa da doença. In: $18^{\mathrm{a}}$ reunião da ANPOCS Grupo de trabalho pessoa, corpo e doença. Salvador; 1994.

6. Foucault M. L'Archéologie du savoir. Paris: Gallimard; 1969.

7. Gancho CV. Como analisar narrativas. $7^{\mathrm{a}}$ ed. São Paulo: Ática; 2003.

8. Foucault M. L'Ordre du discours. Paris: Gallimard; 1971

9. Foucault M. A ordem do discurso. São Paulo: Loyola; 1996.

10. Peres UT. Depressão e melancolia. Rio de Janeiro: Jorge Zahar; 2003.

11. Ricouer P. Teoria da interpretação. Rio de Janeiro: Ed. 70; 1976.

12. Cordeiro E. Foucault e a existência do discurso. Cad Noroeste. 1995;8(1):179-86

13. Foucault M. A arqueologia do saber. Rio de Janeiro: Forense; 1986.
14. Good BJ. Medicine, rationality, and experience: an antropological perspective. Cambridge: Morgan; 1995.

15. Jovchelovitch S, Bauer MW. Entrevista narrativa. In: Bauer MW, Gaskell G. Pesquisa qualitativa com texto, imagem e som: um manual prático. Petrópolis (RJ): Vozes; 2002. p. 91.

16. Bernstein B. The structuring of pedagogic discourse. Londres: Routledge; 1990

17. Spencer JC. The usefulness of qualitative methods in rehabilitation: issues of meaning of context and of change. Arch Phys Med Rehabil. 1993;74(2):119-26.

18. Nogueira-Martins MCF. Humanização das relações assistenciais: a formação do profissional de saúde. São Paulo: Casa do Psicólogo; 2001.

19. Farr RM. Interviewing: the social psychology of the inter-view. In: Fransella F, editor. Psychology for occupational therapists. London: Macmillan; 1982. p.151-70.

20. Santos BS. Um discurso sobre as ciências. Porto: Afrontamento; 1987.

21. Solomon A. Demônio do meio-dia: uma anatomia da depressão. Rio de Janeiro: Objetiva; 2002.

22. Ricouer P. Time and narrative. Chicago: The University of Chicago Press; 1988.

23. Rolin Neto ML. A depressão infantil como experiência familiar. [Relatório de Pós-Doutorado]. São Paulo: Faculdade de Saúde Pública, Universidade de São Paulo; 2011. 